\title{
A sociologia funcionalista nos estudos organizacionais: foco em Durkheim.
}

\author{
Augusto Cabral*
}

\begin{abstract}
Resumo
0 tema que estrutura este ensaio é 0 da sociologia funcionalista, particularmente em termos de sua influência nos estudos organizacionais. 0 seu foco de análise é duplo. Em um primeiro momento, as obras de Durkheim. Em um segundo momento, 0 impacto e a supremacia dos enfoques funcionalistas nos estudos organizacionais. Embora seus segmentos estejam inter-relacionados, ele é composto de quatro partes. Na primeira, é feita uma análise histórica da emergência e sistematização das ciências sociais, de modo a traçar sua evolução até o surgimento dos trabalhos de Durkheim. Na segunda, tomando como referencial a obra de Burrell e Morgan (1979), é estudado o paradigma funcionalista em termos de sua origem e expoentes, com destaque para Comte e Spencer, visando chegar a uma compreensão inicial do pensamento de Durkheim e de sua sociologia. Na terceira, a vida e as principais obras de Durkheim são sumariadas e discutidas. Por fim, o status atual dos estudos organizacionais - vistos como um conjunto impreciso, elástico e eclético de teorias e pesquisas sociais voltados para os problemas das organizações - é analisado em termos de seus pressupostos epistemológicos e ontológicos subjacentes, como meio de explicitar a supremacia dos enfoques positivistasfuncionalistas.
\end{abstract}

Palavras-chave: Sociologia Funcionalista; Estudos Organizacionais; Durkhein.

\begin{abstract}
The theme of this paper is the functionalist sociology in terms of its influence on the organizational studies. First, it focuses on the works of Durkheim. Then, it focuses on the supremacy of the functionalist approaches in the field of organizational studies. The paper is made up of four parts. The first analyzes the emergency of the social sciences in such a way as to trace back the evolution of the field to the works of Durkheim. The second, based on the works of Burrel and Morgan (1979), examines the funcionalist paradigm in terms of its origins and expoents. In this section, special emphasis is given to the works of Comte and Spencer as a means to the understanding of Durkheim's thought and sociology. The third part summarizes the life and works of Durkheim. The last part analyzes the status quo of the organizational studies in terms of their epistemological and ontological assumptions as a way to point out the supremacy of the positivistfuncionalist approaches in the field.
\end{abstract}

Keywords: Funcionalist Sociology; Organizational Studies; Durkhein.

\section{A emergência das ciências sociais}

Embora desde a antiga Grécia, homens como Sócrates - preocupado com a definição de conceitos, na busca pela essência das coisas - e Platão - com seu empenho em mostrar o caminho a ser seguido para ir da doxa (opinião) à episteme (ciência) - tenham buscado um saber mais rigoroso, o conhecimento científico é relativamente recente. Somente ao procurar o seu próprio caminho, o seu método (já na Idade Moderna), a ciência se desvincula da filosofia e passa a determinar objetos específicos a serem apreendidos e controlados com esse método. Em vez de uma ciência, surgem, gradativamente, ciências particulares, com campos mais ou menos delimitados de pesquisa. Esse avanço ocorreu a partir do século XVII e tem a revolução galileana como um dos seus marcos.

* Professor da Universidade Federal do Ceará (UFC). Doutor em Administração pela UFMG. Mestre em Administração pela UECE e Mestre em Educação pela University of New Hamshire/EEUU. E-mail: cabral@ ufc.br.

Artigo recebido em dezembro de 2003 e aceito em fevereiro de 2004. 
Ao defender a substituição do modelo ptolomaico do mundo (o geocentrismo) pelo modelo copernicano (o heliocentrismo), Galileu provocou uma revolução não apenas científica, mas, também, política e epistemológica. Retirando a terra do centro do universo, a nova visão quebrava hierarquias, democratizava espaços e transformava visões de mundo. De seu papel contemplativo, a ciência, em sintonia com o então emergente novo modo de produção capitalista, vai se libertando da teologia para assumir um papel ativo como técnica e tecnologia de conhecimento e dominação das forças da natureza. Na nova ordem burguesa, a ciência se solidifica, impondo o racionalismo no lugar da fé e do dogmatismo; a técnica, a observação e a experimentação no lugar da contemplação, e, sobretudo, o antropocentrismo no lugar do teocentrismo dominante na Idade Média. Em parte, é também de Galileu a herança da "matematização" da ciência como forma de se atingir uma linguagem rigorosa, precisa e capaz de evitar ambigüidades. Para Galileu, o método, o caminho científico é constituído do encontro da matemática com a experimentação. As transformações ocorridas podem ser resumidas em quatro aspectos básicos (ARANHA e MARTINS, 1993, p.146-147):

- a secularização da consciência - o abandono da dimensão religiosa do saber medieval através da separação entre razão e fé, entre verdades científicas e verdades reveladas;

- a descentralização do cosmos - o deslocamento não apenas do lugar da terra no universo, mas do lugar do homem nesse universo;

- a geometrização do espaço - o fim da mistificação do lugar, da "sacrilização" do espaço, que se torna homogêneo e quantificável, logo, mensurável; e

- mecanicismo - o equacionamento da natureza e do homem com a máquina, com um conjunto de mecanismos regidos por leis, implicando a exclusão da ciência de considerações éticas, morais, e filosóficas.

O poder demonstrado pelas ciências naturais na descrição, previsão e explicação de fenômenos resultou na convicção de que também as questões sociais e humanas poderiam ser estudadas sob a nova ótica científica, positivista e mecanicista. Foi então, a partir do século XVIII, que as ciências sociais começaram a constituir um campo coeso e sistemático. Ao estudo da sociedade, buscava-se adaptar os métodos de pesquisa do mundo natural. Esses primeiros enfoques enfatizavam a formulação e o teste de hipóteses para explicação e predição de fenômenos, e também o uso de experimentos controlados e de técnica estatísticas para determinar correlações entre fenômenos. Ainda bastante comum atualmente entre os cientistas sociais com orientações e objetivos semelhantes aos dos cientistas naturais, esse padrão de investigação é, genericamente, conhecido como naturalismo ou positivismo, e no campo das ciências humanas tem Durkheim como um dos maiores expoentes.

Estabelecendo a tirania da observação objetiva dos fatos, o positivismo fixou para as ciências, inclusive as humanas, e dentre estas a sociologia, critérios metodológicos rígidos. É no rastro dessas amarras - ao insistir que o estudo da sociedade devia abster-se do reducionismo e considerar os fenômenos sociais sui generis como coisas - que Durkheim desenvolveu o seu método sociológico. Rejeitando interpretações inspiradas na psicologia ou na biologia, ele concentrou seu foco de atenção, por vezes de forma exagerada, nos determinantes socioestruturais dos problemas humanos. Como Aranha e Martins (1993, p.188) observam, "essa preocupação em tornar o sujeito das ciências humanas um objeto semelhante ao das ciências da natureza marcou com cores fortes a primeira tendência metodológica."

Embora a supremacia dos enfoques positivistas mais ortodoxos seja mais branda na atualidade, ela continua se impondo. Em parte, por se verem presos aos rigores do positivismo, os cientistas sociais têm lutado para construir suas explicações sobre um sólido alicerce de dados fatuais. Desse modo, enfatiza Scott (1990, p.54), “o 'status' dos dados disponíveis deve, portanto, submeter-se a um rigoroso exame de controle de qualidade", uma vez que a qualidade da evidência disponível para análise constitui a base da pesquisa científica. Ainda de acordo com Scott (1990, p.6), um conjunto de critérios relativamente simples pode ser utilizado para avaliar essa qualidade, independentemente do tipo de evidência com que se lida:

- autenticidade - a evidência é genuína e de origem inquestionável?

- credibilidade - a evidência é livre de erros e distorções? 
- representatividade - a evidência é típica de sua categoria, e, se não, a extensão de sua atipicidade é conhecida?

- significado - a evidência é clara e compreensível?

Mais do que uma lista de tarefas a ser checada, os critérios de avaliação são incorporados ao saber do pesquisador experiente, tendendo, portanto, a serem utilizados de forma sutil, não rígida. Esses critérios são interdependentes. A aplicação de um implica invocar as conclusões que derivam da aplicação dos demais. Nesse sentido, dado que quaisquer conclusões alcançadas podem ser utilizadas para levar à avaliação da qualidade, um pouco mais adiante, o processo de avaliação é infindável. Portanto, o significado interpretativo dos resultados apresentados pelo pesquisador é, na verdade, um julgamento inicial e provisório que deve ser revisto à medida que novas descobertas o levam a reavaliar suas evidências (Scott, 1990, p.35). De qualquer maneira, o cientista social deve estar atento para uma questão: facts are not raw perceptions but are theoretically constructed observations (Scott, 1990, p.54).

Ao longo das últimas décadas, a palavra positivismo têm assumido diferentes conotações e tem sido utilizada não apenas de forma exaustiva, mas também, por vezes, de modo inadequado. Segundo Giddens (1997, p.167), “"positivismo' tornou-se antes uma expressão ofensiva do que um termo técnico de filosofia." Confirmando essa constatação, Burrell e Morgan (1994, p.5) argumentam que a palavra positivismo, mais do que um conceito descritivo útil, tornou-se um epíteto derrogatório. A abrangência do termo torna difícil precisar tanto suas fronteiras quanto o seu alvo, confundindo as áreas de exclusão e inclusão. Como um guarda-chuva, o positivismo pode, conforme argumenta Domingues (1998, p.1), recobrir desde o empirismo inglês e o Iluminismo francês do início da modernidade, passando pelo materialismo naturalista do século XIX, até o empirismo lógico e a filosofia analítica do século. XX.

\section{A sociologia funcionalista}

Embora alguns dos elementos do paradigma funcionalista remetam ao pensamento político e social dos gregos antigos, a determinação do seu ponto de origem é difícil. Por conveniência, a sua análise freqüentemente começa com o trabalho de Comte, genericamente visto como o pai da sociologia. Tido como o sociólogo da unidade humana e social (Aron, 1965, p. 59), o filósofo francês Auguste Comte via o conhecimento e a sociedade como estando em um processo evolucionário, cujo estágio "inicial" seria o teológico ou fictício; "intermediário", o metafísico ou abstrato; e "final", o científico ou positivo. Essas etapas foram formuladas em sua obra Curso de filosofia positiva (1830-42), constituindo a chamada "lei dos três estágios", segundo a qual o conhecimento e a sociedade evoluem numa direção bem definida. No primeiro estágio, os fenômenos são explicados por referência à vontade dos deuses e a realidades transcendentes; no segundo, recorre-se a conceitos mais abstratos, referentes a processos universais, como "natureza"; e no terceiro, o conhecimento se baseia na descrição dos fenômenos e na descoberta das leis objetivas que os determinam. A função da sociologia seria, então, compreender o necessário, indispensável e inevitável curso da história, de forma a promover a realização de uma nova ordem social. Para Comte, a racionalidade estava em ascendência, fundamentando a base de uma ordem social bem regulada. $\mathrm{O}$ enfoque positivista estruturaria o destino da humanidade, guiando-a para o tipo de sociedade ideal.

Para Comte, o método positivo - já então reinante na matemática, astronomia, física e biologia - finalmente prevaleceria na política e culminaria na fundação de uma ciência positiva da sociedade, a sociologia. Essa sociologia se baseava em modelos e métodos das ciências naturais. Visava descobrir as leis científicas subjacentes às relações entre as várias partes da sociedade ("estática social") e explicar o modo como elas mudam ao longo do tempo ("dinâmica social"). Tendo sido o criador do termo "sociologia," Comte via a sociedade como um organismo em que cada parte tem uma função específica e contribui para o funcionamento do todo. Como Burrell e Morgan (1994, p.42) ressaltam, Comte associava a biologia à ciência social. Ele via a primeira como um ponto de transição decisivo entre as ciências, no sentido de que marcava uma diferença entre o "orgânico" e o "inorgânico", enfatizando a compreensão e a explicação dentro da totalidade do todo vivo. Baseado no modelo positivo das ciências naturais, utilizando analogias mecânicas e orgânicas, distinguindo entre estática (estrutura) e dinâmica (processo), e defendendo o holismo metodológico, Comte instaurou as 
regras de uma atividade sociológica voltada para a explicação da ordem e da regulação social, tendo dessa forma lançado os alicerces do paradigma funcionalista (Burell e Morgan, 1994, p.42).

Em sua obra, Comte propôs uma classificação do campo do conhecimento e viu na sociologia a mais nova e complexa das ciências "positivas", aquelas voltadas para a observação direta dos fenômenos. O positivismo de Comte, desenvolvido como uma nova doutrina religiosa da humanidade, expandiu sua zona de influência para além da França, e sua máxima, "ordem e progresso", figura até hoje na bandeira brasileira. A respeito desse lema, Giddens (1997, p.180) ressalta que "a dependência mútua entre progresso e ordem é tanto um tema dos escritos de Durkheim quanto dos de Comte." Refletindo o crescente interesse de Comte ao longo de sua vida pelas questões morais, a doutrina positivista buscava ser uma resposta aos desafios da sociedade moderna, também uma preocupação central em Durkheim. Em relação ao impacto de Comte sobre a sociologia de Durkheim em particular e a sociologia em geral, Giddens (1997, p.178) afirma que:

"Tanto quanto se concebe a ciência social do século XX, a influência dos escritos de Comte deriva menos do seu impacto direto do que de seu remanejamento na versão de Durkheim do método sociológico. As obras de Durkheim oferecem uma fonte próxima para o funcionalismo tanto em antropologia quanto em sociologia. Mas a obra de Durkheim também teve um efeito amplo e mais difuso, como um estímulo para as tradições centrais do pensamento social contemporâneo em que a finalidade de atingir uma "ciência natural da sociedade" é considerada desejável e factível."

Outro positivista influente, tanto na constituição do funcionalismo (Burrell e Morgan, 1994, p.43) quanto na formação de Durkheim, foi Herbert Spencer, embora, como enfatiza Giddens (1997, p.180), fique claro que "Durkheim deduziu sua concepção de método funcionalista de Comte e não de Spencer", uma vez que "Durkheim seguiu Comte de perto ao separar a explicação funcional (estática) da explicação histórica (dinâmica), ainda que criticasse tanto Comte quanto Spencer por reificarem o "progresso": tratar o ímpeto para o auto-aperfeiçoamento como se fosse uma causa geral da evolução da sociedade."

Positivista na tradição de Comte, a principal contribuição de Spencer, como indicam Burell e Morgan (1994, p.43), foi desenvolver de forma mais detalhada as implicações da analogia biológica para a sociologia. Influenciado por Darwin, Spencer via o estudo da sociologia como o estudo da evolução em sua forma mais complexa. Embora vendo a sociedade como um tipo de organismo, ele usava a analogia de forma flexível, mais como um instrumento explicativo. Nesse sentido, seu trabalho contribuiu muito para a fundação da análise dos fenômenos sociais em termos de "estrutura" e "função".

Spencer traçou paralelos entre a evolução das sociedades e a das espécies, enfatizando o papel do conflito, incluindo a guerra, como uma força para a mudança social. Essa evolução, entretanto, era vista de uma perspectiva teórica que enfatizava a inevitável marcha em direção aos sistemas sociais mais complexos e integrados, cuja forma mais avançada era a sociedade industrial. Como Parsons salientou, o Deus de Spencer era a evolução, às vezes denominado progresso (Burrell e Morgan, 1994, p.43). Para Giddens (1997, p.180), as idéias de Comte eram, na realidade, mais próximas das de Spencer do que este admitia.

\section{Durkheim - vida e obra}

Nascido em 15 de abril de 1858 em Épinal, França, Durkheim, ao lado de Max Weber, pode ser visto como o fundador da sociologia como disciplina acadêmica. Mesmo como estudante de filosofia na École Normale Supérieure, de Paris, Durkheim já demonstrava inquietação em relação aos problemas sociais. Ao retornar de um período de estudos na Alemanha, criou em Bordeaux, em 1887, uma cátedra de sociologia e educação, a primeira a existir na França. Sendo ele um jovem cientista social, a sua nomeação para a Faculdade de Letras de Bordeaux - cujo corpo docente era predominantemente humanista - despertou forte oposição. Ao enfatizar o valor da sociologia para as disciplinas humanas mais tradicionais como a filosofia, a história e o direito, Durkheim suscitou temores justificáveis de um "imperialismo sociológico" (JONES, 1986). Em 1902, essa situação de conflito trouxe-lhe dificuldades quando conseguiu realizar seu sonho de lecionar em Sorbonne, Paris, algo que também era a pretensão de muitos acadêmicos franceses. 
Sendo por formação um filósofo de universidade francesa com formação laica (ARON, 1987), Durkheim se empenhou no desenvolvimento de um corpo de seguidores intelectuais que viria a publicar o jornal fundado por ele em 1896, L'Annee Sociologique, cujo objetivo era promover os pontos de vista do grupo através da pesquisa de vários assuntos. Entre os discípulos, estavam Marcel Mauss, Marcel Granet, Georges Davy, Robert Hertz, Francois Simiand, e Maurice Halbwachs. Como resultado, a influência de Durkheim é ainda muito forte, não somente na sociologia moderna, mas também na antropologia, lingüística, direito, teologia, psicologia e em toda a historiografia francesa.

Em sua época, Durkheim teve lugar de destaque no tratamento de questões sociológicas empíricas, o que repercurte ainda hoje. Graças ao vigor e ao alcance de seu trabalho em diversas frentes, Durkheim pode ser descrito, como o fez Parsons (1972, p.319), como um eficiente empreendedor da sociologia. Entretanto, pondera Parsons, seu brilhantismo advém, sobretudo, do fato dele ter utilizado as referências e estruturas de tradições intelectuais solidamente estabelecidas como o utilitarismo inglês, o idealismo germânico, além de sua própria bagagem francesa, para formular uma estrutura referencial firmemente embasada nessas tradições, sendo, ao mesmo tempo, bastante original. Sua morte prematura em 15 de novembro de 1917, aos 59 anos, pode, talvez, ser atribuída aos choques causados pelo guerra que além de ter matado vários de seus colegas e amigos, matou o seu próprio filho em 1916.

Em termos de orientação intelectual, a formação de Durkheim era majoritariamente de origem francesa, remetendo a Decartes e Rosseau, de uma perspectiva mais distante, e a figuras como Saint-Simon, Auguste Comte, Herbert Spencer e ao seu próprio professor, Fustel de Coulanges, dentre outros, de uma perspectiva mais próxima. A preocupação de Durkheim com as correntes contemporâneas dominantes na Inglaterra e na Alemanha é, como salienta Parsons (1972p.312), tipicamente francesa, pois, na verdade, a originalidade do pensamento francês preenchia uma lacuna intermediária entre as duas principais linhas de pensamento européias, o empirismo e o utilitarismo inglês e o idealismo alemão. Assim,

"In a crucial sense, modern sociology is a product of the synthesis of elements that have figured most prominently in these two traditions, and it seems to have been the mediating character of his French background that gave Durkheim a distinctive 'place to stand', from which he contributed so effectively to this synthesis."

A herança de Comte e Spencer em Durkheim foi assimilada de modo crítico. A influência de Comte não foi em termos de continuidade, mas sim de formação, e teve como traço mais forte a extensão da atitude positiva, científica, em relação ao estudo da sociedade. Apesar de Durkheim discordar de Comte em vários aspectos, a noção "durkheimiana" da realidade objetiva dos "fatos sociais" reflete a influência da visão "comtiana" de uma realidade social concreta; logo, objeto de investigação científica racional. Tendo reconhecido que Comte havia simplificado essa realidade ao ignorar o modo como a sociedade é composta de diferentes "tipos" e "espécies", Durkheim achou a análise de Spencer mais aceitável, e incorporou muitos dos insights deste - derivados da analogia orgânica - à sua própria visão. Porém, para Durkheim a sociologia tinha de ir além: a mera análise das partes existentes no organismo social e do papel que elas desempenham não era adequada como um fim de análise social. A análise causal era necessária além da "análise funcional" (Burrell e Morgan, 1994, p.44). Em termos de método, Durkheim, a exemplo de Comte e Spencer, inspirou-se nas ciências naturais, amoldando-se ao paradigma fisicalista. Na construção de seu método sociológico, ele

“...expurga os elementos metafísicos da doutrina de Comte (por ex. a teoria dos três estados), retém sua motivação empírica e lhe estende a matemática e a estatística. Assim, estabelece no plano do método 1) o preceito de observação objetiva e imparcial dos fenômenos (traduzido no famoso imperativo das Regras de tomar os fatos sociais como coisas, sem nenhuma idéia prévia ou noção preconcebida), 2) a necessidade de estabelecer conexões causais entre os fenômenos e conferir-lhes a forma da lei, segundo o número e a medida (como as taxas do suicídio), 3) a exigência de submeter as proposições da sociologia à verificação empírica (a exemplo dos vaticínios sobre a religião com base na indução, nas Formas Elementares da Vida Religiosa)" (DOMINGUES, 1998, p.2). 
Considerado um holista metodológico, distinguindo entre causas, funções e estruturas, Durkheim enriqueceu o pensamento de seus antecessores e forneceu uma sólida base para o desenvolvimento do paradigma funcionalista. Quanto à sua teorização, Durkheim se situa no contexto da sociologia da regulação. Sua sociologia reflete uma preferência pela ordem como força principal nas questões sociais, como ressaltam Burrell e Morgan (1994, p.44-45). Sua preocupação com o status quo, a ordem social, o consenso, a integração e coesão social, e a solidariedade o caracterizam como um legítimo sociólogo da ordem e da regulação.

Durkheim argumentava que uma das tarefas dos sociólogos era estudar os determinantes sociais do comportamento - "deveres, leis, e costumes" - que unem e mantêm as pessoas em sociedade. Em sua inquietação com as mazelas sociais, ele identificava duas concepções de solidariedade, a mecânica, associada às sociedades tradicionais, e a orgânica, associada às sociedades industriais. Para ele, as "sociedades tradicionais" se mantinham unidas pela "solidariedade mecânica", que deriva da semelhança das partes e tem a "consciência" do indivíduo como um simples apêndice e seguidor da consciência coletiva (DURKHEIM, 1938, p.148). A "consciência coletiva" se baseava num sistema compartilhado de valores, normas e crenças. Na sociedade industrial, com seu sistema de divisão de trabalho e diferenciação funcional, ele via uma solidariedade orgânica advinda da interdependência das partes. Durkheim reconheceu que no processo de transição das sociedades tradicionais para as industriais, a solidariedade poderia romper-se, criando um estado de anomia ou anormalidade. Porém, ele via isso como um estado patológico no curso natural de desenvolvimento.

De uma perspectiva crítica, Jones (1986), ressalta alguns traços marcantes em Durkheim: o uso insistente de argumentação por eliminação; a utilização constante de petitio principii em sua argumentação, uma falácia em que a premissa de um argumento presume a própria conclusão a ser argumentada; a insistência em proclamar a sociologia como uma ciência independente, com sua própria e irredutível realidade, o que o levou a adotar uma linguagem excessivamente metafórica (por exemplo, as analogias biológicas e mecânicas); o uso impreciso ou demasiadamente elástico de conceitos, como o de coerção; além do fato de que suas explicações macrosociológicas pressupõem uma teoria sociopsicológica nunca explicitada.

\section{Principais obras}

O cerne do pensamento de Durkheim pode ser ressaltado pela análise de seus principais livros: $A$ divisão do trabalho social (1893), As regras do método sociológico (1895), O suicídio (1897), e As formas elementares da vida religiosa (1912). Algumas das idéias básicas de cada um deles são apresentadas em seguida numa síntese que de forma alguma busca ser exaustiva. Fora os aspectos metodológicos desenvolvidos em seus livros, Durkheim trata fundamentalmente da questão do consenso.

O primeiro desses livros, A divisão do trabalho social é, de fato, a tese de doutoramento de Durkheim. Nele, Durkheim trata das relações entre os indivíduos e a coletividade, uma preocupação central no pensamento do autor, tendo como ponto de questionamento o desafio de como manter um grau satisfatório de coerência moral e intelectual nas sociedades modernas, caracterizadas pela extrema especialização de funções.

Durkheim estuda a passagem entre o que chamou de solidariedade mecânica e solidariedade orgânica. A primeira, característica das sociedades "simples," um tipo de organização social que teria se dissolvido à medida que a sociedade se tornava mais diferenciada. A segunda, característica das sociedades modernas baseadas na divisão do trabalho. Nestas, a família passa a ser econômica e socialmente secundária em relação ao trabalho, e as expectativas que orientam o comportamento social tornam-se mais específicas, variando segundo os papéis desempenhados pelos indivíduos. Durkheim acreditava que essa era uma forma mais frágil de sociedade, mais sujeita a conflitos e ao enfraquecimento das regras formais ou informais que asseguram a coesão social, a anomia. Mais do 
que como um fenômeno humano, Durkheim via a lei da divisão do trabalho aplicável não apenas às sociedades humanas, mas aos organismos biológicos em geral. Sendo a divisão do trabalho uma lei natural, Durkheim refletia sobre os questionamentos morais que dela advinham e que, para ele, as sociedades modernas não vinham enfrentado de modo apropriado, criando, assim, uma situação de conflito moral que ele buscou primeiro explicar e depois resolver.

Convencido de que os fatos morais como a divisão do trabalho eram em si fenômenos naturais constituídos por regras de ação impostas à conduta - que podiam ser reconhecidas, observadas, descritas, classificadas e explicadas -, Durkheim utilizou o método da chamada "ciência da ética" na explicação e resolução dessa situação. Para ele, a explicação era apenas um passo na solução de problemas sociais práticos, pois concebia a sociedade como estando sujeita às condições de saúde ou doença moral, sendo o sociólogo o seu médico. Definido o problema dessa forma, sua solução implicava a determinação da função da divisão do trabalho, a determinação das causas de que essa divisão dependia e a determinação das formas de "doença" que ela exibia (JONES, 1986, p.25). A palavra função refere-se à (JONES, 1986, p.26):

- sistema de movimentos vitais (digestão, respiração etc.) sem referência às conseqüências desses movimentos; e

- relação entre esses movimentos e as correspondentes necessidades do organismo (a digestão incorpora alimentos essenciais ao corpo, a respiração leva para dentro do organismo os gases necessários etc.). Durkheim enfatiza a segunda opção, a divisão do trabalho em termos da necessidade orgânica que esta preenchia.

Durkheim se preocupava em diferenciar as causas de um fato social de suas funções. Também à análise da divisão do trabalho, ele impunha essa diferenciação, insistindo que suas causas não poderiam ser algum tipo de antecipação de seus efeitos morais, pois esses efeitos se tornaram evidentes somente após um longo processo de evolução social e dificilmente poderiam ser previstos. Tendo descartado as causas individualistas e psicológicas, Durkheim argumentava que a explicação para a divisão do trabalho deve ser buscada em alguma variação dentro do contexto social. Fundamental, portanto, era o estudo das formas de organização social. Segundo Durkheim, para constituir uma sociedade, os indivíduos devem alcançar o consenso por meio da solidariedade, mecânica ou orgânica, que representam formas extremas de organização social. Os traços de cada uma delas são sumariadas a seguir:

- solidariedade mecânica - típica das sociedades tradicionais, primitivas ou arcaicas. É representada pela metáfora da máquina. É uma solidariedade por semelhança, característica das sociedades em que os indivíduos são "intercambiáveis" por diferirem pouco uns dos outros, reconhecem os mesmos objetos como sagrados, têm os mesmos sentimentos e valores, além do fato de que são orientados pelos imperativos e proibições sociais.

A sociedade tem coerência porque os indivíduos ainda não se diferenciaram. A implicação é a de que o indivíduo não vem historicamente em primeiro lugar, uma idéia central no pensamento de Durkheim;

- solidariedade orgânica - típica das sociedades industriais, modernas. É representada pela metáfora do organismo. É uma solidariedade por diferenciação, característica das sociedades em que os indivíduos não são "intercambiáveis", diferem uns dos outros e têm a liberdade de crer, querer e agir conforme suas preferências.

Os indivíduos diferem uns dos outros porque ocorre o consenso, o qual resulta da diferenciação ou se exprime por seu intermédio.

A divisão do trabalho de Durkheim é diferenciada, em termos de enfoque, daquela estudada pelos economistas, como ressalta Aron (1987, p.299). A diferenciação das profissões e a multiplicação das atividades industriais oriundas da desintegração da solidariedade mecânica e da estrutura segmentária - exprimem a diferenciação social que Durkheim prioriza. Da análise desses temas decorrem idéias que fazem parte da teoria geral de 
Durkheim, como, por exemplo, o conceito de "consciência coletiva", significando o conjunto das crenças e sentimentos comuns à média dos membros de uma sociedade que forma um sistema determinado, com vida própria. A consciência coletiva existe em função dos sentimentos e crenças presentes nas consciências individuais, mas não é apenas a expressão ou efeito destas. A consciência coletiva evolui segundo suas próprias leis e tem maior extensão nas sociedades dominadas pela solidariedade mecânica.

Ao elaborar essas noções, Durkheim conclui que o indivíduo nasce da sociedade, e não o contrário. Surge daí uma de suas idéias centrais, a definição da sociologia como a prioridade do todo sobre as partes, ou a irredutibilidade do conjunto social à soma dos elementos, e a explicação dos elementos pelo todo. Como Aron enfatiza (1987, p.302), no estudo da divisão do trabalho, Durkheim descobriu:

- a prioridade histórica das sociedades onde a consciência individual está inteiramente fora de si; e

- a necessidade de explicar os fenômenos individuais pelo estado da coletividade, e não o estado da coletividade pelos fenômenos individuais.

Para Durkheim, a definição científica da divisão do trabalho era apenas uma etapa. O estudo científico de um fenômeno social exigia, em sua opinião, uma metodologia específica, objetiva. Como afirma Aron (1987, p.302), tratava-se de identificar "o meio pelo qual os estados de consciência não perceptíveis diretamente podem ser reconhecidos e compreendidos. Estes sintomas, ou expressões dos fenômenos de consciência são, em De la division du travail social, os fenômenos jurídicos." Entra em cena a caracterização de um dos tipos de solidariedade, o direito repressivo que pune faltas e crimes e revela a consciência coletiva nas sociedades de solidariedade mecânica; e o direito "restitutivo", voltado para o restabelecimento do estado das coisas e que não é a única forma de direito característica das sociedades de solidariedade orgânica. Da manipulação interligada desses conceitos e noções, Durkheim esboça uma teoria do crime, da qual tira uma teoria das sanções.

Durkheim preocupa-se com as formas anormais da divisão do trabalho. Partindo do pressuposto de que a divisão do trabalho é cada vez mais uma das pilastras da ordem social, ele propõe criar uma ciência moral, para analisar como a evolução das formas sociais repercute no caráter das normas morais, conforme ressalta Aron (1987, p.305). Ele rebate a teoria utilitarista, segundo a qual o aumento da especialização do trabalho gera um aumento de riqueza; logo, maior satisfação das necessidades humanas e felicidade. A elevação do índice de suicídio nas sociedades modernas é o argumento utilizado. Em seu esforço de encontrar a causa do desenvolvimento da divisão do trabalho nas sociedades modernas, um fenômeno social, Durkheim recorre ao princípio da homogeneidade da causa e do efeito, que postula que um fenômeno social só pode ser explicado por outro fenômeno social. No caso, o de uma combinação de volume, número de indivíduos; densidade material, número de indivíduos em relação a uma dada área, além de densidade moral, intensidade das comunicações e trocas entre os indivíduos da sociedade. Já para explicar o mecanismo da diferenciação social, Durkheim usa o conceito de luta pela vida, de Darwin, que possibilita uma perspectiva coerente com o que Durkheim considera uma regra do método sociológico: a explicação de um fenômeno social por outro fenômeno social e a explicação de um fenômeno global por outro fenômeno global.

Nos livros de Durkheim é evidente a semelhança dos métodos usados e dos resultados obtidos. Neles, Durkheim define o fenômeno, refuta as interpretações anteriores e elabora uma explicação propriamente sociológica do fenômeno estudado.

As regras do método sociológico - concebido quando Durkheim refletia sobre $A$ divisão do trabalho e $O$ suicídio - representa a formulação abstrata da prática dos dois primeiros livros. Seus tópicos incluem:

- "o conceito de fato social" - modos de fazer ou pensar reconhecíveis por poderem exercer coerção sobre as consciências particulares;

- "as regras para a observação dos fatos sociais" - considerar esses fatos sociais como coisas e afastar sistematicamente todas as noções prévias;

- "as regras para distinção do normal do patológico" - procurar manifestações exteriores, imediatamente perceptíveis mas objetivas, que nos permitam reconhecer as duas ordens de fatos; 
- "as regras para a constituição dos tipos sociais" - escolher para a classificação, traços particularmente essenciais;

- "as regras para a explicação dos fatos sociais" - investigar separadamente a causa eficiente que produz um dado fenômeno social e a função que ele desempenha; e

- "as regras para a demonstração da prova sociológica" - para verificar se um fenômeno é causa de outro, comparar os casos em que estes estão simultaneamente presentes ou ausentes e observar se as variações apresentadas comprovam a dependência de um em relação ao outro (a um mesmo efeito corresponde sempre uma mesma causa).

A concepção da sociologia de Durkheim se baseia em uma teoria do fato social. Para ele, pode e deve haver uma sociologia objetiva e científica - nos moldes das ciências já estabelecidas - cujo objeto é o fato social. Essa sociologia requer que seu objeto seja específico, distinto do das demais ciências, e que possa ser observado e explicado como ocorre nessas outras ciências. Duas proposições fundamentam a metodologia de Durkheim:

- os fatos sociais devem ser considerados como coisas (tudo o que nos é dado e/ou se impõe à nossa observação);

- a característica básica de tais fatos é que eles exercem uma coerção sobre os indivíduos. O termo coerção tem uma pluralidade de sentidos (regras jurídicas, morais, dogmas religiosos, sistemas financeiros) que consistem em crenças e práticas constituídas. Consistem ainda em fatos sociais que, sem apresentarem essas formas organizacionais, têm a mesma objetividade sobre o indivíduo (como, por exemplo, as correntes sociais de entusiasmo, indignação e piedade).

Conhecer os fenômenos sociais, os fatos, como coisas implica a adoção de uma postura metodológica rígida e objetiva, nos padrões de Durkheim, que permitam uma observação asséptica, a exemplo do enfoque usado na física e na biologia. Em sua teoria sociológica, os problemas de definição e de classificação têm lugar de destaque. Em seus livros, Durkheim começa por definir o fenômeno considerado, uma tarefa fundamental, uma vez que trata de isolar uma categoria de fatos. Definida uma dada categoria de fatos, Durkheim julga ser possível encontrar uma única explicação para eles. Um efeito determinado provém sempre da mesma causa. Em relação a esse método, Aron (1987, p.340) aponta um perigo duplo: "substituir imperceptivelmente uma definição, intrínseca, por outra, extrínseca, relacionada com sinais exteriores reconhecíveis, e pressupor arbitrariamente que todos os fatos classificados nessa categoria derivam necessariamente de uma mesma causa."

Em $O$ suicídio, Durkheim, de forma pioneira, empregou sistematicamente dados estatísticos para a elucidação de questões sociais. A relação do indivíduo com o grupo e com as normas e valores prevalecentes no grupo é a preocupação maior no livro, que parte da hipótese de que as causas do suicídio estão nas condições sociais. Para testar essa teoria, Durkheim estudou registros de taxas de suicídio em todos os países europeus em que havia dados disponíveis. Algumas dessas estatísticas haviam sido coletadas por outros pesquisadores; outras estavam disponíveis em documentos públicos; fora as que tinham sido compiladas de arquivos oficiais. Com relativa ingenuidade, Durkheim examinou essas estatísticas em termos do impacto que exerciam sobre diferentes hipóteses. Primeiro, ele examina um número de hipóteses alternativas: que o suicídio é o resultado de estados psicopáticos, de imitação, de fatores raciais ou hereditários, de fatores cósmicos. Demonstra que as estatísticas não condizem com qualquer dessas hipóteses. Parte para novas hipóteses e análises. Através de uma série de análises, demonstra que as regularidades sazonais nas taxas de suicídio não podem ser explicadas pela temperatura, e sugere a hipótese alternativa de que a atividade social é sazonal e que a taxa de suicídio está relacionada com o grau de atividade social.

Considerando a hipótese de que uma causa básica de suicídio é a falta de integração no grupo social, ele examina três influências sociais principais: religião, família, e atmosfera política. Descobre, por exemplo, que as taxas de suicídio são mais baixas entre os católicos do que entre os protestantes, entre as pessoas casadas do que as solteiras, entre as pessoas com filho do que as sem filhos, e durante os períodos de fervor nacional. Há uma tendência ao aumento da frequiência dos suicídios tanto nos períodos de crise econômica quanto nos de 
prosperidade, e há uma tendência à redução da frequiência dos suicídios durante os grandes acontecimentos políticos. Todas essas descobertas, ele argumenta, apoiam a hipótese de que pertencer a um grupo social coeso é um empecilho para o suicídio. À medida que analisava seus dados, ele modificava e refinava sua teoria. Entretanto, seus estudos suscitam algumas questões, dentre elas o valor das estatísticas, a validade da correlações estabelecidas, bem como a relação entre a interpretação sociológica e a psicológica. Um ponto central é o de que a evidência a partir da qual Durkheim extraiu seus dados é de qualidade duvidosa. Como Scott (1990, p.53) salienta, para que suas conclusões possam ser consideradas, os problemas de credibilidade e significado, negligenciados por Durkheim, devem ser reduzidos a um patamar em que se possa estabelecer com algum grau de certeza quais eram as reais taxas de suicídio.

Para Durkheim (1960, p.5), suicídio é "todo caso de morte provocado direta ou indiretamente por um ato positivo ou negativo realizado pela própria vítima e que ela sabia que devia provocar este resultado." Essa definição requer a compreensão de que um ato positivo/direto seria, por exemplo, disparar um tiro na cabeça, como um ato negativo/indireto seria, por exemplo, não abandonar uma casa em chamas. Logo, o conceito de suicídio engloba não só os casos reconhecidos por todos, mas também as mortes voluntárias envoltas em heroísmo e glória, como indica o seguinte esquema de tipos de suicídio:

- egoísta - analisado graças à correlação entre a taxa de suicídio e os contextos sociais integradores, a religião e a família, esta última considerada sob o duplo aspecto de casamento e prole;

- altruísta - analisado em dois exemplos principais: o completo desaparecimento do indivíduo no grupo (a viúva indiana que aceita ser colocada na fogueira que queima o corpo do marido e o comandante do navio que não quer sobreviver à perda de sua nave). Há, portanto, dois tipos básicos na "corrente suicidógena": os que se afastam demais do grupo social e os que estão demasiadamente presos ao grupo;

- anômico - revelado pela correlação estatística entre a frequiência do suicídio e as fases do ciclo econômico. Atinge os indivíduos em função das condições de vida nas sociedades modernas, onde a existência social não é regulamentada pelos costumes, sendo, portanto, o tipo que mais interessava à Durkheim.

Um fato essencial para Durkheim é o de que, sendo característica de uma sociedade global, ou de uma dada região, a taxa de suicídio é relativamente constante. Ela varia em função de múltiplas circunstâncias. Ao sociólogo, cabe estabelecer correlações entre as circunstâncias e as variações dessa taxa. Variações que são fenômenos sociais.

Durkheim distingue o fenômeno individual da taxa de suicídio, que é um fenômeno social. O importante é a relação entre o fenômeno individual (suicídio) e o fenômeno social (taxa de suicídio). De acordo com a definição do fenômeno, Durkheim afasta as explicações de tipo psicológico, embora reconheça que possa haver uma predisposição psicológica. Porém, o fator determinante é social. Como coloca Aron (1987, p.310), a discussão científica está centrada nesses dois termos, "predisposição psicológica" e "determinação social". Para demonstrar essa distinção, Durkheim emprega o método clássico das variações concomitantes. Estuda as variações da taxa de suicídio em diferentes populações e procura provar que não há correlação entre a frequiência dos estados psicopatológicos e a frequiência dos suicídios.

Interessado nas consequiências práticas do estudo do suicídio, Durkheim o estudava em termos de seu caráter "normal" ou "patológico". Para ele, os suicídios são fenômenos individuais, cujas causa são, contudo, essencialmente sociais. As causas reais dos suicídios são forças sociais que variam de sociedade para sociedade, de grupo para grupo e de religião para religião. Como ressalta Aron (1987, p.315), mais uma vez, temos aqui o tema fundamental da sociologia de Durkheim: as sociedades têm natureza diferente da dos indivíduos. Existem fenômenos e forças cujo suporte é a coletividade e não a soma dos indivíduos.

O suicídio tem o rigor de um trabalho acadêmico e constitui uma aplicação de seu método sociológico:

- definição do fenômeno a ser estudado;

- refutação das interpretações anteriores;

- estabelecimento de uma tipologia; 
- desenvolvimento de uma teoria geral do fenômeno, considerado a partir da tipologia estabelecida.

Em As formas elementares da vida religiosa, Durkheim visa elaborar uma teoria geral da religião, com base na análise das instituições mais simples e mais primitivas. As conclusões extraídas do estudo do totemismo australiano pressupõem que seja possível apreender a essência de um fenômeno, observando suas formas mais elementares. O livro reúne, como demonstra Aron (1987, p.322), uma descrição e análise do sistema de clãs e do totemismo de certas tribos australianas, uma teoria da essência da religião e uma interpretação sociológica das formas do pensamento humano, ou seja, uma introdução à sociologia do conhecimento. O método é o mesmo das obras anteriores: definição do fenômeno, refutação das teorias diferentes, demonstração da natureza essencialmente social das religiões.

A essência da religião é a divisão do mundo em fenômenos sagrados e profanos, e não a crença em divindades transcendentes. Depois de definir a religião, Durkheim afasta as interpretações anteriores à sua: o animismo, a fé em espíritos e o naturismo, a fé em forças naturais transfiguradas. Em ambos, segundo Durkheim, termina-se por dissolver o objeto considerado. A religião corresponde a uma alucinação coletiva. Por outro lado, Durkheim acredita poder explicar a realidade do fenômeno religioso. Para Aron (1987, p.325), a visão do totemismo como a religião mais simples implica uma representação evolucionária da religião, o que caracteriza Durkheim como um pensador evolucionista. Essa visão admite não apenas que há um processo evolucionista de desenvolvimento da religião, a partir de uma origem única, mas também que uma experiência específica pode revelar a essência de um fenômeno comum a todas as sociedades. Entretanto, como Jones (1986) salienta, a escolha do caso único leva Durkheim a ignorar evidências contrárias. Ademais, não há necessariamente uma relação entre a simplicidade de uma sociedade e a simplicidade de suas práticas religiosas, assim como não há também uma relação necessária entre totemismo e religião.

Partindo do pressuposto de que o totemismo australiano era o tipo mais simples de sistema religioso conhecido, Durkheim concluiu que ele esclareceria os principais elementos da religião em geral. Porém, o totemismo das tribos enfocadas não era sequer típico do totemismo australiano em geral, e muito menos dos sistemas totêmicos de outras partes do mundo. Além disso, muitos antropólogos passaram a considerar o totemismo não como uma forma de religião, mas como forma de ritual e organização de parentesco (Giddens, 1981, p.75-89). Por sua vez, Jones (1986) observa que a análise do material relativo ao totemismo e às tribos enfocadas têm levado críticos a sugerir que os dados australianos foram adotados simplesmente para ilustrar as teorias de Durkheim, ao invés de as teorias terem sido construídas ou adaptadas para dar conta dos dados.

Como já observado, a teoria durkheimiana de religião depende da polaridade do sagrado e do profano, como esferas discretas e opostas. Contudo, essa polaridade não é universal, embora possa ser observada em certos sistemas religiosos. Durkheim baseou sua teoria da religião numa sociedade estruturalmente muito simples, sem hierarquias. Assim, além de ignorar as relações de poder, essa visão reforçou sua tendência de falar de "sociedade" como de uma entidade homogênea. Como ressalta Giddens (1981, p.77), ao contrário de Weber e Marx, ele não enfrenta a possibilidade das crenças religiosas serem ideologias que ajudam a legitimar a dominação de alguns. O conflito era visto em termos de oposições entre o indivíduo e a coletividade, um fenômeno de fases de transição no desenvolvimento social, em que a harmonia das funções está temporariamente suspensa. Para ele, as sociedades são conjuntos unificados cuja base de unidade está associada à solidariedade mecânica ou à orgânica.

Há duas interpretações da sociologia da religião de Durkheim (ARON, 1987, p.330). A de que no totemismo os homens adoram, sem saber, a sociedade, o que significa que o sagrado está vinculado em primeiro lugar à força coletiva e impessoal que é uma representação da própria sociedade. E a de que as sociedades criam deuses ou religiões quando entram num estado de exaltação da própria vida coletiva. Nas sociedades arcaicas, as cerimônias ritualísticas; nas modernas, as crises políticas e sociais. A partir dessas idéias, Durkheim desenvolve uma interpretação das noções de alma, espírito e Deus, conforme a lógica das representações religiosas. Além disso, ele evidencia a importância de dois tipos de fenômenos sociais, os símbolos e os ritos, chamando atenção para o fato de que muitas das condutas sociais se dirigem não para as coisas em si mesmas, mas para seus símbolos. 
Durkheim tira do estudo do totemismo uma teoria sociológica do conhecimento. Além de estudar as crenças e práticas das tribos, ele reflete também sobre as maneiras de pensar associadas às crenças religiosas e verifica que a religião não é apenas o núcleo de onde saíram regras morais e religiosas, mas é também a origem do pensamento científico. Sua teoria sociológica tem três proposições (ARON, 1987, p.332):

- as formas primitivas de classificação estão ligadas às imagens religiosas do universo, retiradas das representações que as sociedades fazem de si mesmas, e da dualidade do mundo profano e religioso ou sagrado;

- uma idéia como a da causalidade provém da sociedade, e só dela pode provir;

- a teoria sociológica do conhecimento fornece o meio para superar a oposição entre o empirismo e o apriorismo, ambos falsos para Durkheim. A síntese necessária vai resultar da intervenção da sociedade.

\section{0 funcionalismo nos estudos organizacionais}

Apesar das mudanças constatadas no campo dos estudos organizacionais ao longo do século, o enfoque científico, alicerçado nos parâmetros funcionalistas, continua sendo o "ethos prevalecente" de pesquisa, como salienta Bryman (1982, p.32). Embora à primeira vista possa parecer bastante eclético, o campo dos estudos organizacionais é composto, majoritariamente, de teorias e pesquisas que se encaixam no paradigma funcionalista. Em termos de pressupostos, o grau de concentração é tão grande que, segundo Burrell e Morgan (1994, p.121), mesmo dentro desse paradigma, a grande maioria dos estudos e teorias apresenta um ponto de vista funcionalista particular, a da teoria dos sistemas sociais e objetivismo.

Essa aparente diversidade se manifesta, em grande parte, graças aos diversos esquemas classificatórios que têm sido propostos por diferentes autores, quer em termos de tipologias - frequientemente rivais, baseadas em funções, tecnologia, regulação, ou estrutura - quer em termos de desenvolvimento histórico, baseado em explicações lineares, descontextualizadas. São propostos ainda em termos de análise individual, grupal, ou organizacional, e em termos cujo ponto de vista considerado é o dos gerentes ou o dos demais atores organizacionais. Em qualquer dos casos, os pressupostos subjacentes aos enfoques apresentados permanecem inexplorados, o que tem implicado uma proximidade bem maior entre essas várias correntes sugeridas nos debates acadêmicos sobre o tema (BURRELL e MORGAN, 1994, p.120). O debate enfoca apenas detalhes, tendo sempre um tom "amigável" e "construtivo", girando em torno das melhorias técnicas que podem ser feitas ainda que de uma perspectiva funcionalista como um todo, advertem Burrell e Morgan (1994, p.218). Segundo esses autores, a estrutura do paradigma funcionalista está baseada em quatro pontos de vista:

- teoria dos sistemas sociais - constituída pelo "funcionalismo estrutural" e pela "teoria dos sistemas", que utilizam analogias biológicas e mecânicas ao tratar das questões sociais, representa um desenvolvimento do positivismo sociológico em sua forma mais pura;

- interacionismo e teoria da ação social - unem elementos do positivismo sociológico e do idealismo alemão, constituindo, assim, a fronteira mais subjetiva do paradigma funcionalista;

- teoria integrativa - com uma posição central no paradigma, busca preencher a lacuna entre a teoria dos sistemas sociais e o interacionismo, sem se comprometer com nenhuma das duas; sendo constituída pelo "funcionalismo do conflito", pela "teoria morfogênica dos sistemas", pela "teoria da troca e poder de Blau" e pela "teoria da estrutura social e cultural de Merton";

- objetivismo - próxima da teoria dos sistemas, por seu vínculo com o positivismo sociológico, diferencia-se desta por seu apego a modelos/métodos das ciências naturais e é formada pelo "behaviorismo", derivado de modelos fisiológicos usados na psicologia, e do "empiricismo abstrato", dominado por metodologias quantitativas, sem atributos sociais.

Em sua visão de mundo social, os funcionalistas tendem a ver a sociedade como ontologicamente anterior ao homem, colocando o homem e suas atividades dentro desse contexto maior. Ao assumir o ponto de vista do observador, relacionam aquilo que observam ao que julgam importante no contexto maior, acreditando, 
contudo, não afetarem o objeto observado. Pressupõem a existência de padrão e ordem contínuos; logo, buscam explicar a natureza regulamentada das questões sociais. Entretanto, admitem, ao mesmo tempo, um certo grau de ordem e desordem, consenso e dissenso, integração e desintegração, satisfação e frustração em suas explicações sobre como a sociedade permanece unida. Com sua concepção racionalista de ciência, acreditam na inquisição objetiva capaz de fornecer conhecimento explicativo e verdadeiro sobre a realidade externa, pressupondo que as teorias científicas podem ser objetivamente avaliadas, tendo como referência a evidência empírica. Crêem, ainda, que existem regras governando o mundo externo e que padrões de ciência externos e universais determinam o que constitui uma explicação adequada de um dado fenômeno.

Essa noção racional de ciência e de conhecimento válido é imposto pelos funcionalistas. A ciência, usada como um instrumento de regulação, explica o mundo social em termos de estruturas e funções físicas e biológicas similares àquelas do mundo natural. Desse modo, a diversidade existente entre as correntes alinhadas ao paradigma funcionalista se prende sempre a essa concepção de mundo e de ciência, sendo, pois, uma diversidade superficial manifestada em termos de grau e não de pressupostos. Por vezes, mascara uma estratégia de defesa:

"Building upon basic models derived from the natural sciences (as modified by Comte, Spencer, Pareto and Durkheim), sociologists have responded to the external challenge and threat posed by alternative intellectual traditions through both fusion and incorporation (...) elements of German idealism have been fused with the Anglo-French tradition to produce interactionism. Aspects of the work of Marx has been incorporated into integrative theory. In each case the rival intellectual tradition has been sucked into the paradigm and used in a manner which defies certain of its basic assumptions. In other words, 'these different intellectual traditions have been reinterpreted from a functionalist perspective"” (BURREL e MORGAN, p.108 - destaque do autor).

Apesar de ser possível abordar o funcionalismo de vários pontos de vista, segundo Slabbert (1976), existem duas características que devem sempre estar presentes em qualquer análise. Primeiro, o fato que uma explicação funcional é sempre teológica, fornecida em termos de um esquema "de meios-e-fins". Segundo, a idéia de sistema, em relação a qual Slabbert enfatiza que, ao contrário do sistema mecanicista-determinista tradicional, um sistema funcional tem que lidar com as mudanças nos relacionamentos entre as variáveis do sistema e as variáveis ambientais. De modo complementar, Kast e Rosenzweig (1987, p.125), ao manifestarem uma concepção de Merton, mostram que o funcionalismo, apesar de suas várias conotações, enfatiza essencialmente sistemas de relacionamento e a unificação das partes e dos subsistemas em uma totalidade funcional, na qual cada elemento tem uma função a desempenhar no sistema mais amplo.

O funcionalismo está presente em praticamente todas as ciências sociais, desde a sociologia, a psicologia e a antropologia até a jurisprudência e a lingüística. Também na administração, de modo direto ou não, aparece em abordagens que vão desde a chamada escola clássica - normalmente tida como a primeira corrente sistematizada de pensamento, surgida nas primeiras décadas deste século, e à qual se alinham, dentre outros, Taylor e Fayol - até o chamado movimento de qualidade de vida. Este ganhou ímpeto já a partir da década de 1970, visando solucionar os problemas trazidos pela transição da sociedade industrial para a sociedade pósindustrial, numa retomada "inconsciente" (ou nem sempre declarada), de uma antiga inquietação durkheimiana, num novo contexto. Nesse sentido, a retomada de temas e enfoques com raízes funcionalistas é freqüente, como tende a ser freqüente a não alusão à essas inspirações. Burrell e Morgan (1994, p.138) salientam, por exemplo, que o modelo de Hawthorne - associado à escola de relações humanas - pode ser melhor compreendido como uma fusão de elementos da sociologia de Pareto e Durkheim.

A análise da evolução da perspectiva funcionalista nas teorias organizacionais deixa claro que mesmo as abordagens aparentemente mais modernas, inovadoras e radicais, tais como a contingencial e a da qualidade de vida no trabalho, são meras variações disputadas nos limites do paradigma funcionalista. Ilustrando essa realidade, Burrell e Morgan (1994, p.184) afirmam que "whereas contingency theory stands as the contemporary equivalent of classical management theory, the quality of working life movement stands as the contemporary equivalent of the industrial psychology and human relations movements." Independentemente do discurso 
proferido, o foco é nas contribuições a serem feitas para a estabilidade e sobrevivência do sistema total, o que muda são os ingredientes e a dosagem aplicada.

\section{Conclusão}

O funcionalismo pode e tem sido enfocado de diferentes perspectivas, não havendo, de fato, nenhuma abordagem particularmente mais importante ou significativa. De modo geral, ele "procura ver as ciências sociais em termos de estruturas, processos e funções, e compreender as relações existentes entre esses componentes. Ele realça que cada elemento de uma cultura ou instituição social tem uma função a desempenhar no sistema mais amplo" (KAST e ROSENZWEIG, 1987, p.125).

O conceito de função teve papel importante em várias obras de Durkheim, como, por exemplo, em seu esforço para explicar em A divisão do trabalho social as funções da divisão do trabalho, na tentativa de mostrar quais necessidades sociais ela satisfazia, da mesma forma que em As formas elementares da vida religiosa ele busca demonstrar as funções dos cultos, ritos e crenças na sociedade. Como afirma Coser (1997, p.140), foi Durkheim quem estabeleceu a lógica do enfoque funcional para o estudo do fenômeno social, embora explicações funcionais e alguns vestígios desse padrão de raciocínio já fossem encontrados nos trabalhos de Spencer e Comte. Recusando não apenas a perspectiva de análise fundamentada em causas e origens históricas, mas também aquela fundamentada em motivações e propósitos individuais, Durkheim instituiu a análise funcional como meio de apreensão da realidade social.

Embora vários aspectos do trabalho de Durkheim tenham sido mencionados aqui, muitos outros não o foram, como por exemplo, as suas contribuições no campo da sociologia da educação e da sociologia do direito. Essa ausência se deve principalmente à falta de espaço. Ainda que algumas críticas aos trabalhos de Durkheim tenha sido apresentadas, essa linha de análise não era o objetivo particular deste texto. Uma preocupação maior foi a de delimitar a lógica do seu enfoque funcionalista e a perspectiva positivista de pesquisa, ressaltando não apenas seus preceitos básicos, mas também algumas de suas falhas. Em termos de crítica, Domingues (1998, p.2) ressalta, por exemplo, que "além de dar expressão ao conhecimento científico (ao qual julga ou pretende como conhecimento científico), o positivismo legifera sobre ele e estabelece normas e prescrições de toda sorte, violando o preceito de primeiro observar e descrever os fatos e só depois fazer a teoria dos mesmos."

Outro tema tratado foi o do status dos estudos organizacionais na atualidade. Como enfatizam Clegg e Hardy (1996, p.110), as mudanças ocorridas têm resultado em crescente pluralidade. Entretanto, a diversidade visível acaba por mascarar meras variações de estilo limitadas ao contexto do paradigma funcionalista e, desse modo, tem implicado a perpetuação não de uma hegemonia, mas de uma supremacia. 


\section{Referências bibliográficas}

ARANHA, M.; MARTINS, M. Filosofando: introdução à filosofia. São Paulo: Moderna, 1993.

ARON, R. As etapas do pensamento sociológico. 2. ed. São Paulo: Martins Fontes, 1987.

BRYMAN, A. Research methods and organization studies. 2. ed. London: Routledge, 1982.

BURRELL, G.; MORGAN, G. Sociological paradigms and organizational analysis. London: Heinemann Educational Books, 1979.

Arena, $19 \overline{9} \overline{4}$.

Sociological paradigms and organizational analysis: elements of the sociology of corporate life. 9. ed. Hants, Inglaterra:

CLEGG, S.; HARDY, C.; NORD, W. (Eds.). Handbook of organization studies. London: Sage, 1996.

COSER, L. Masters of sociological thought: ideas in historical and social context. London: Hbj College and School Division, 1997.

DOM INGUES, I. Positivismo e ciências humanas. Cepead - UFMG, 1998. (Notas de aula). No prelo.

DURKHEIM, E. Division du travail social. Paris: Alcan, 1893.

. Les règles de la méthode sociologique. Paris: Alcan, 1895.

Le suicide: etude de sociologie. Paris: Alcan, 1897

. Les formes élementaires de la vie religieuse: le système totémique en Australie. Paris: Alcan, 1912.

. As regras do método sociológico. In: Émile Durkheim. São Paulo: Abril Cultural, 1978.

GIDDENS, A. As idéias de Durkheim. São Paulo: Cultrix, 1981.

Política, sociologia e teoria social: encontros com o pensamento social clássico e contemporâneo. São Paulo: Unesp, 1997.

JONES, R. Émile Durkheim: an introduction to four major works. Beverly Hills, CA: Sage Publications, 1986.

KAST, F.; ROSENZWEIG, J . Organização e administração: um enfoque sistêmico. 3. ed. São Paulo: Pioneira, 1987.

MORGAN, G. Paradigm diversity in organizational research. In: HASSAR, J.; PYM, D. (Eds.). The theory and philosophy of organizations: critical issues and new perspectives. London: Routledge. 1990. p.13-29.

PARSON, T. Durkheim, Émile. In: SILLS, D. (Ed.). International encyclopedia of the social sciences. Reprint edition. New York: MacMillan; The Free Press, 1972. v.4, p.311-320.

SCOTT, J. A matter of record: documentary sources in social research. Cambridge: Polity Press, 1990.

SLABBERT, J. Functional methodology in the theory of action. In: LOUBSER, J., et al. (Eds.). Explorations in general theory in social science: essays in honor of Talcott Parsons. New York: The Free Press, 1976. v. 1, p. 46-58. 